\title{
Prognostic value of circulating tumor cells in advanced gastric cancer patients receiving chemotherapy
}

\author{
YONGPING LIU ${ }^{1,2}$, YANG LING ${ }^{1,2}$, QIUFENG QI $^{1}$, FENG LAN ${ }^{1}$, MING ZHU ${ }^{1}$, \\ YAPING ZHANG $^{1}$, YANQING BAO ${ }^{1}$ and CHANGSONG ZHANG ${ }^{1}$ \\ ${ }^{1}$ Clinical Oncology Laboratory; ${ }^{2}$ Department of Oncology, Changzhou Tumor Hospital \\ Affiliated to Suzhou University, Changzhou, Jiangsu 213002, P.R. China
}

Received October 14, 2015; Accepted November 17, 2016

DOI: $10.3892 / \operatorname{mco} .2017 .1125$

\begin{abstract}
The identification of circulating tumor cells (CTCs) may provide important prognostic information in several types of solid tumors, including gastric cancer. The aim of this study was to investigate whether CTC count may be used to predict survival in patients with advanced gastric cancer treated with chemotherapy. The CELLection ${ }^{\mathrm{TM}}$ EpithelialEnrichkit was used to isolate and purify CTCs from samples of peripheral blood. Immunofluorescent staining was used for CTC counting. High CTC counts were associated with poor tumor differentiation and high serum CEA levels ( $\mathrm{P}=0.021$ and 0.005 , respectively). After 3 months, 16 patients with decreasing CTC counts after the first cycle of chemotherapy obtained complete response, partial response or stable disease, while 13 patients with increasing CTC counts developed progressive disease. The patients with decreasing CTC counts also exhibited longer progression-free survival $(\mathrm{PFS})(\mathrm{P} \leq 0.001)$ and overall survival $(\mathrm{OS})(\mathrm{P}=0.002)$ compared with those with increasing CTC counts. Among all 59 patients, those with a CTC count of $\leq 2$ cells $/ 5 \mathrm{ml}$ blood exhibited longer PFS $(\mathrm{P} \leq 0.001)$ and $\mathrm{OS}(\mathrm{P} \leq 0.001)$ compared with those with a CTC count of $>2$ cells $/ 5 \mathrm{ml}$ blood. The multivariate analysis suggested that an increase of the CTC count after the first cycle of chemotherapy was only an independent prognostic marker of poor PFS $(\mathrm{P}=0.019)$. However, a baseline CTC count of $>2$ cells $/ 5 \mathrm{ml}$ blood was an independent poor prognostic marker for PFS $(\mathrm{P}=0.008)$ and $\mathrm{OS}(\mathrm{P}=0.001)$ in all 59 patients. Our study suggested that patients with a low baseline CTC count or decrease of the CTC count after the first cycle of chemotherapy may benefit significantly from palliative chemotherapy. In conclusion, CTC count may be a good chemotherapy monitoring marker and an ideal prognostic marker for patients receiving palliative chemotherapy.
\end{abstract}

Correspondence to: Professor Yongping Liu, Clinical Oncology Laboratory, Changzhou Tumor Hospital Affiliated to Suzhou University, 1 North Huaide Road, Changzhou, Jiangsu 213002, P.R. China

E-mail: liuyongping026@126.com

Key words: circulating tumor cells, chemotherapy, objective response, survival, gastric cancer

\section{Introduction}

Palliative combination chemotherapy has become the standard of care for patients with advanced gastric cancer, as it is effective in prolonging survival and improving the quality of life (1). The short-term efficacy is usually assessed after 2 or 3 cycles of chemotherapy. The objective response (OR) to chemotherapy is the primary study endpoint, which is essential for assessing prognosis and planning further treatment (2). However, $\sim 50 \%$ of patients with advanced gastric cancer may not benefit from chemotherapy, which may be determined prior to the second cycle of chemotherapy. Computed tomography (CT) scans are often used by physicians to evaluate the OR to chemotherapy in cancer patients (3). However, due to its radiation-associated risks and low sensitivity, CT is not suitable for assessing the OR to chemotherapy within a shorter period of time.

Identifying these non-responding patients within a shorter time period may represent a challenge for most physicians. Thus, the development of easier, cost-effective and safer tools for monitoring the effects of chemotherapy in gastric cancer patients would be of great value. Several studies recently investigated the prognostic relevance of circulating tumor cell (CTC) count in patients with solid tumors $(4,5)$, including gastric cancer (6). Hematogenous metastasis is one of the main ways of malignant tumor metastasis. Thus, the majority of patients with advanced cancer have tumor cells in their peripheral blood. Detection of CTCs may be more sensitive compared with CT and other imaging tests for monitoring the chemotherapeutic effects. In this study, immunomagnetic enrichment was used to isolate and purify CTCs from peripheral blood, followed by fluorescein isothiocyanate (FITC)-labeled anti-cytokeratin (CK) 7/8/18/19 antibody staining and fluorescence microscope identification of CTCs, in order to investigate the prognostic and predictive values of CTC count determination in advanced gastric cancer patients who receive palliative combination chemotherapy.

\section{Materials and methods}

Patients and treatment protocols. Tumor specimens were collected from 59 gastric cancer patients with stage II-IV disease, who were recruited between January, 2011 and 
June, 2013 and underwent chemotherapy at the Department of Oncology, Changzhou Tumor Hospital (Changzhou, China). The patients comprised 35 men and 24 women, with a median age of 59 years (range, 35-81 years). None of the patients had received previous chemotherapy. Histologically or cytologically confirmed gastric cancer and confirmation of the clinical stage based on the results of examination by chest X-ray and CT scan of the chest and abdomen. All the patients received at least 3 cycles of paclitaxel at $60 \mathrm{mg} / \mathrm{m}^{2}$ i.v. guttae on days 1,8 and 15 , with cisplatin $25 \mathrm{mg} / \mathrm{m}^{2}$ i.v. guttae on days $1-3$, followed by continuous infusion of $500 \mathrm{mg} / \mathrm{m}^{2}$ 5-fluorouracil on days 1-5.

This study was approved by the local Ethics Committee and written informed consent was obtained from all the patients prior to enrolment.

Remission analysis. Tumor response was assessed according to the Response Evaluation Criteria in Solid Tumors (7): Complete response (CR) was defined as disappearance of all target lesions; partial response (PR) was defined as at least a $30 \%$ decrease in the sum of the diameters of target lesions, taking as reference the baseline sum of the diameters; progressive disease (PD) was defined as at least a $20 \%$ increase in the sum of the diameters of the target lesions, taking as reference the smallest sum on study. In addition to the relative increase of $20 \%$, the sum must also demonstrate an absolute increase of $\leq 5 \mathrm{~mm}$; and stable disease (SD) was defined as neither sufficient shrinkage to qualify as PR nor sufficient increase to qualify as PD, taking as reference the smallest sum of the diameters while on study.

Follow-up. Interim history, physical examination, hematological studies, measurement of serum carcinoembryonic antigen (CEA) and carbohydrate antigen (CA) 19-9 levels and whole-body CT were performed every 3 months during the first year and every 6 months thereafter. Progression-free survival (PFS) was defined as the time from study entry until disease progression, death, or the day of the last follow-up visit, whichever came first. Overall survival (OS) was defined as the time from study entry until the date of death, regardless of the cause, or the most recent documented follow-up visit.

Blood sample collection from patients and healthy donors. Peripheral blood samples were collected to investigate the presence of CTCs prior to the administration of the first cycle of chemotherapy (baseline) and prior to the second cycle of chemotherapy in patients with advanced gastric cancer. For blood spiking experiments and to be used as controls, peripheral blood samples were also collected from 9 healthy donors. All the blood samples were collected in EDTA-coated tubes (S-Monovette ${ }^{\circledR}$; Sarstedt, Nümbrecht, Germany). To avoid epithelial cell contamination from the skin puncture, the first $5 \mathrm{ml}$ of peripheral blood were stored for other studies. After collection, the blood samples were immediately processed for further experiments.

Cell spiking experiments. For cell spiking experiments, SGC-7901 gastric cancer cells expressing epithelial cell adhesion molecule (EpCAM), CK7, CK8, CK18 and CK19, were serially diluted in 5-ml blood samples collected from 5 different healthy donors. The dilutions applied were as follows: $10^{3}, 10^{2}, 10$ and 0 SGC-7901 cells per $5 \mathrm{ml}$ whole blood. The SGC-7901 human gastric cancer cell line was obtained from the Shanghai Cell Bank of Chinese Academy of Sciences (Shanghai, China). The cells were cultured in RPMI-1640 medium (Gibco BRL, Gaithersburg, MD, USA), supplemented with $10 \%$ bovine serum, penicillin $\left(100 \mathrm{U} \mathrm{ml}^{-1}\right)$, streptomycin $\left(100 \mu \mathrm{g} \mathrm{ml}^{-1}\right)$, pyruvate, glutamine and insulin at $37^{\circ} \mathrm{C}$ in a water-saturated atmosphere with $5 \% \mathrm{CO}_{2}$. The collection of cells was performed using Trypsin-EDTA (Gibco BRL) and centrifugation at room temperature for $3 \mathrm{~min}$ at $300 \mathrm{x}$ g. The cells were then counted using a hemocytometer (Ningbo Hinotek Co., Ltd., Zhejiang, China) and cell viability was confirmed by trypan blue staining.

Mononuclear cell (MNC) collection. The MNC population was extracted according to the following protocol: 5-ml peripheral blood samples were carefully layered onto a 15-ml Ficoll gradient (FicoLite-H ${ }^{\circledR}$, density: $1.077 \mathrm{~g} / \mathrm{ml}$; Linaris, Wertheim, Germany) and covered with $10 \mathrm{ml}$ phosphate-buffered saline (PBS) solution (PAA Laboratories GmbH, Pasching, Austria). The samples were spun in a centrifuge at $4^{\circ} \mathrm{C}$ for $30 \mathrm{~min}$ at $300 \mathrm{x} \mathrm{g}$ without brake. Concentrated MNCs were harvested from the interface using a disposable pipette. The isolated cells were washed once in PBS, spun in a centrifuge for $10 \mathrm{~min}$ at $300 \mathrm{x} \mathrm{g}$ and resuspended in $1 \mathrm{ml}$ PBS. The MNCs were counted with a hemocytometer and resuspended at a density of $10^{7}$ cells $/ \mathrm{ml}$ in PBS.

Immunomagnetic enrichment and immunofluorescence staining. The blood samples from the patients and the spiked (with SGC-7901 cells) blood samples $(5 \mathrm{ml}$ blood for each experiment) of healthy volunteers were processed using CTC immunoisolation with the CELLection ${ }^{\mathrm{TM}}$ Epithelial Enrich kit following manufacturer's protocol (Invitrogen Dynal, Oslo, Norway). Following EpCAM-based immune enrichment, the isolated CTCs were stained with 4',6-diamidine-2'-phenylindole dihydrochloride (DAPI) (Roche Molecular Biochemicals, Mannheim, Germany) and FITC-labeled anti-CK7/8/18/19 antibody (polyclonal, rabbit, specific for CK7/8/18/19 of human; dilution, 1:200, cat. no. RE-1588R-FITC; Yanjing Biotech Co., Ltd., Shanghai, China) following the manufacturer's protocol; subsequently, the CTCs were counted by fluorescence microscopy. CTCs were identified as the cells showing a fluorescent signal of anti-CK7/8/18/19-FITC in the cytoplasm and specific DAPI staining in the nucleus. Finally, in cell spiking experiments, we calculated the percentage of CTC recovery as follows: CTC recovery $\%=$ no. of CTCs recovered from $5 \mathrm{ml}$ blood/no. of SGC-7901 cells added to $5 \mathrm{ml}$ blood $\mathrm{x} 100 \%$.

Statistical methods. Statistical significance was based on a two-sided significance level of 0.05. All the analyses were performed with SPSS software, version 17.0 (SPSS Inc., Chicago, IL, USA). The differences in the values among the groups under study were assessed using the analysis of independent samples t-test, as indicated. The association between CTC count and clinicopathological characteristics was analyzed by the Chi-square test. The paired-samples t-test was used to compare CTC counts prior to and following chemotherapy. 
Table I. Circulating tumor cell (CTC) recovery percentages in cell spiking experiments.

\begin{tabular}{lcccccc}
\hline \multirow{2}{*}{$\begin{array}{l}\text { SGC7901 } \\
\text { cell number }\end{array}$} & $\mathrm{A}$ & $\mathrm{B}$ & $\mathrm{C}$ & $\mathrm{D}$ & $\mathrm{E}$ & Mean value \pm SD \\
\cline { 2 - 7 } & & & & & \\
\hline 0 & $0(0.0)$ & $0(0.0)$ & $0(0.0)$ & $0(0.0)$ & $0(0.0)$ & $0 \pm 0(0.0 \pm 0.0)$ \\
10 & $5(50.0)$ & $4(40.0)$ & $1(10.0)$ & $3(30.0)$ & $6(60.0)$ & $3.8 \pm 1.9(38.0 \pm 19.2)$ \\
100 & $39(39.0)$ & $43(43.0)$ & $37(37.0)$ & $52(52.0)$ & $41(41.0)$ & $42.4 \pm 5.9(42.4 \pm 5.9)$ \\
1,000 & $361(36.1)$ & $432(43.2)$ & $422(42.2)$ & $415(41.5)$ & $523(52.3)$ & $430.6 \pm 58.5(43.06 \pm 5.9)$ \\
\hline
\end{tabular}

A, B, C, D and E: Cell spiking experiments in peripheral blood from healthy donors A, B, C, D and E, respectively. SD, stadard deviation.

Table II. Associations between CTC counts and clinicopathological features.

\begin{tabular}{|c|c|c|c|c|}
\hline \multirow[b]{2}{*}{ Type } & \multicolumn{2}{|c|}{ CTC } & \multirow[b]{2}{*}{$\chi^{2}$} & \multirow[b]{2}{*}{$\mathrm{P}$-value } \\
\hline & $\leq 2 / 5 \mathrm{ml}$ blood & $>2 / 5 \mathrm{ml}$ blood & & \\
\hline Age (median, 59 years) & & & 2.07 & 0.121 \\
\hline$\leq 59$ & 9 & 21 & & \\
\hline$>59$ & 14 & 15 & & \\
\hline Gender & & & 3.326 & 0.069 \\
\hline Male & 17 & 18 & & \\
\hline Female & 6 & 18 & & \\
\hline $\mathrm{CEA}, \mathrm{ng} / \mathrm{ml}$ & & & 8.361 & 0.005 \\
\hline$<5$ & 20 & 18 & & \\
\hline$\geq 5$ & 3 & 18 & & \\
\hline CA19-9 ng/ml & & & 2.842 & 0.078 \\
\hline$<37$ & 16 & 17 & & \\
\hline$\geq 37$ & 7 & 19 & & \\
\hline Stage & & & 0.116 & 0.762 \\
\hline III & 6 & 8 & & \\
\hline IV & 17 & 28 & & \\
\hline ECOG PS & & & 0.116 & 0.762 \\
\hline 0,1 & 6 & 8 & & \\
\hline 2 & 17 & 28 & & \\
\hline Tumor differentiation & & & 5.281 & 0.021 \\
\hline Poor/undifferentiated & 9 & 25 & & \\
\hline High and moderate & 14 & 11 & & \\
\hline
\end{tabular}

CTC, circulating tumor cell; CEA, carcinoembryonic antigen; CA19-9, carbohydrate antigen 19-9; ECOG PS, Eastern Cooperative Oncology Group performance status; SD, standard deviation.

Kaplan-Meier survival curves and the log-rank test were used to analyze univariate distributions for PFS and OS. The prognostic significance of baseline CTC count and changes of the CTC count following chemotherapy was assessed using Cox proportional hazards regression analysis. $\mathrm{P} \leq 0.05$ was considered to indicate statistically significant differences.

\section{Results}

Specificity and sensitivity of enrichment and extraction protocols. No CK signal was observed in the examined blood samples from the 9 healthy donors, which demonstrated the specificity of the used assays. In serial dilution assays, 10 SGC-7901 cells were detected in $5 \mathrm{ml}$ whole blood, which was repeated in 5 healthy donors. Finally, the percentage of CTC recovery was calculated (Table I).

CTC counts in patients and healthy controls. The average CTC count \pm standard deviation in all 59 patients was $5.95 \pm 8.4 / 5 \mathrm{ml}$ blood; no CK signal was detected in the blood samples from the 9 healthy controls $(0 / 5 \mathrm{ml}$ blood $)$. The CTC-positive rate in the advanced gastric cancer and healthy control groups 
Table III. Factors associated with survival in 59 patients receiving chemotherapy.

\begin{tabular}{|c|c|c|c|c|c|}
\hline Prognostic factors & $\mathrm{n}$ & $\begin{array}{l}\text { Median PFS } \\
\text { (months) }\end{array}$ & P-value & $\begin{array}{c}\text { MST } \\
\text { (months) }\end{array}$ & P-value \\
\hline Gender & & & 0.32 & & 0.208 \\
\hline Male & 35 & 6 & & 11 & \\
\hline Female & 24 & 5 & & 7 & \\
\hline Age, years & & & 0.221 & & 0.169 \\
\hline$\leq 59$ & 30 & 5 & & 7 & \\
\hline$>59$ & 29 & 6 & & 14 & \\
\hline Tumor differentiation & & & 0.141 & & 0.072 \\
\hline Poor/undifferentiated & 34 & 5 & & 7 & \\
\hline High and moderate & 25 & 7 & & 14 & \\
\hline ECOG PS & & & 0.002 & & 0.001 \\
\hline 0,1 & 36 & 7 & & 15 & \\
\hline 0 & 23 & 4 & & 6 & \\
\hline Response & & & 0.01 & & 0.002 \\
\hline $\mathrm{CR}+\mathrm{PR}$ & 29 & 11 & & 17 & \\
\hline $\mathrm{SD}+\mathrm{PD}$ & 30 & 3 & & 6 & \\
\hline CA19-9 ng/ml & & & 0.01 & & 0.002 \\
\hline$\leq 37$ & 33 & 7 & & 14 & \\
\hline$>37$ & 26 & 4 & & 6 & \\
\hline Stage & & & 0.760 & & 0.800 \\
\hline III & 14 & 5 & & 7 & \\
\hline IV & 45 & 5 & & 12 & \\
\hline СТC & & & $<0.001$ & & $<0.001$ \\
\hline$\leq 2$ cells $/ 5 \mathrm{ml}$ peripheral blood & 23 & 11 & & 17 & \\
\hline$>2$ cells $/ 5 \mathrm{ml}$ peripheral blood & 36 & 4 & & 7 & \\
\hline Changes in CTC & & & $<0.001$ & & $<0.001$ \\
\hline Decline & 17 & 10 & & 15 & \\
\hline Increase & 12 & 3 & & 6 & \\
\hline CEA ng/ml & & & $<0.001$ & & $<0.001$ \\
\hline$\leq 5$ & 38 & 7 & & 14 & \\
\hline$>5$ & 21 & 3 & & 6 & \\
\hline
\end{tabular}

CTC, circulating tumor cell; PFS, progression-free survival; MST, median survival time; CEA, carcinoembryonic antigen; CA19-9, carbohydrate antigen 19-9; ECOG PS; Eastern Cooperative Oncology Group performance status; CR, complete response; PR, partial response; SD, stable disease; PD, progressive disease.

was 83.05 and $0 \%$, respectively. In 29 patients who were tested twice, before and after the first cycle of chemotherapy, the mean CTC count $(8.10 \pm 12.64 / 5 \mathrm{ml}$ blood) did not decrease compared with that prior to chemotherapy $(7.24 \pm 10.942 / 5 \mathrm{ml}$ blood) $(\mathrm{P}=0.527)$.

Associations between CTC count and clinicopathological characteristics. High CTC counts were significantly associated with poor tumor differentiation $(\mathrm{P}=0.021)$ and high serum CEA levels $(\mathrm{P}=0.005)$, but not with age, gender, clinical stage or performance status (Table II). It appears that higher serum CA19-9 levels were associated with higher CTC counts, but the difference was not statistically significant $(\mathrm{P}=0.078)$ (Table II).
Associations between changes in CTC count and response in patients tested before and after the first cycle of chemotherapy. Changes in the CTC count in 29 patients who were tested before and after the first cycle of chemotherapy were significantly correlated with efficacy after 3 cycles of chemotherapy. The mean CTC count $(1.2 \pm 2.04$ cells $/ 5 \mathrm{ml}$ blood $)$ after the first cycle of chemotherapy was significantly decreased in patients who obtained CR and PR $(n=15)$, compared with that prior to chemotherapy $(2.53 \pm 3.75$ cells $/ 5 \mathrm{ml}$ blood $)(\mathrm{P}=0.049)$. In patients with PD ( $=7)$, the mean CTC count $(23.43 \pm 17.01 / 5 \mathrm{ml}$ blood $)$ increased significantly, compared with that prior to chemotherapy $(14.71 \pm 16.71 / 5 \mathrm{ml}$ blood $)(\mathrm{P}=0.021)$. The CTC count after 1 month of chemotherapy did not decrease significantly in patients with SD compared with that prior to chemotherapy. 

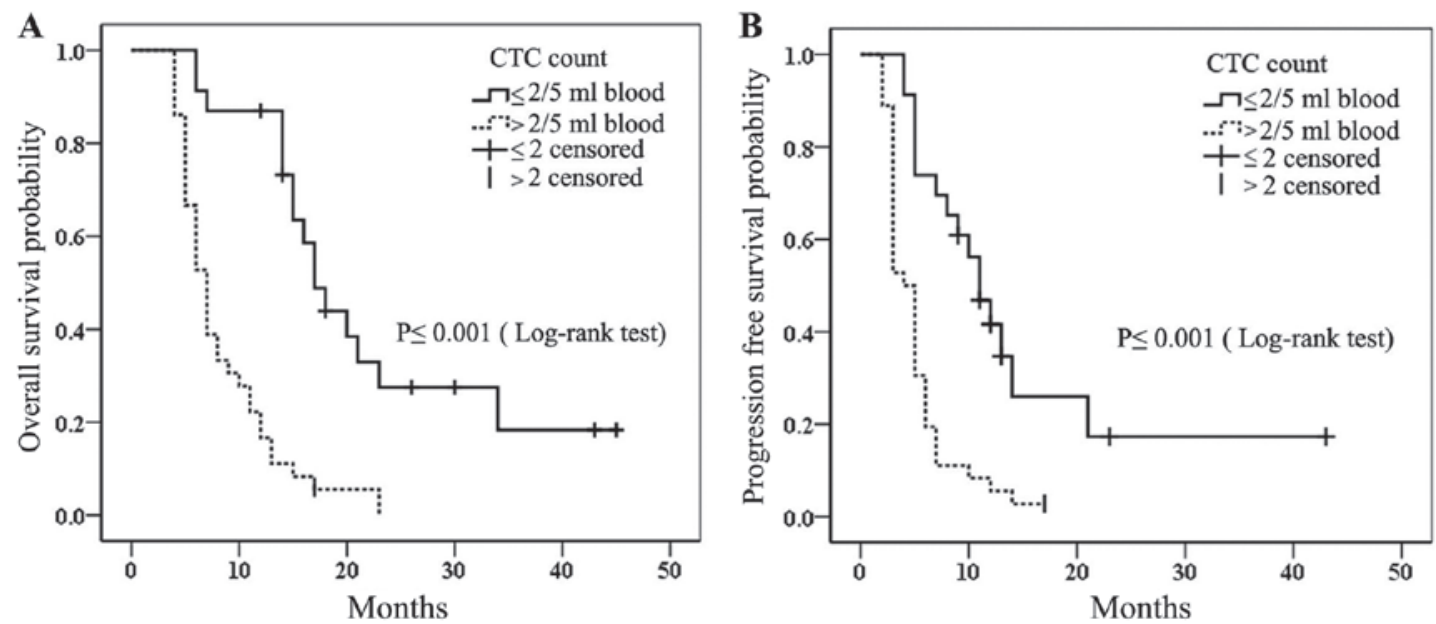

Figure 1. (A) Overall survival curve and (B) progression-free survival curve for all 59 patients who received chemotherapy, according to the baseline circulating tumor cell (CTC) count.
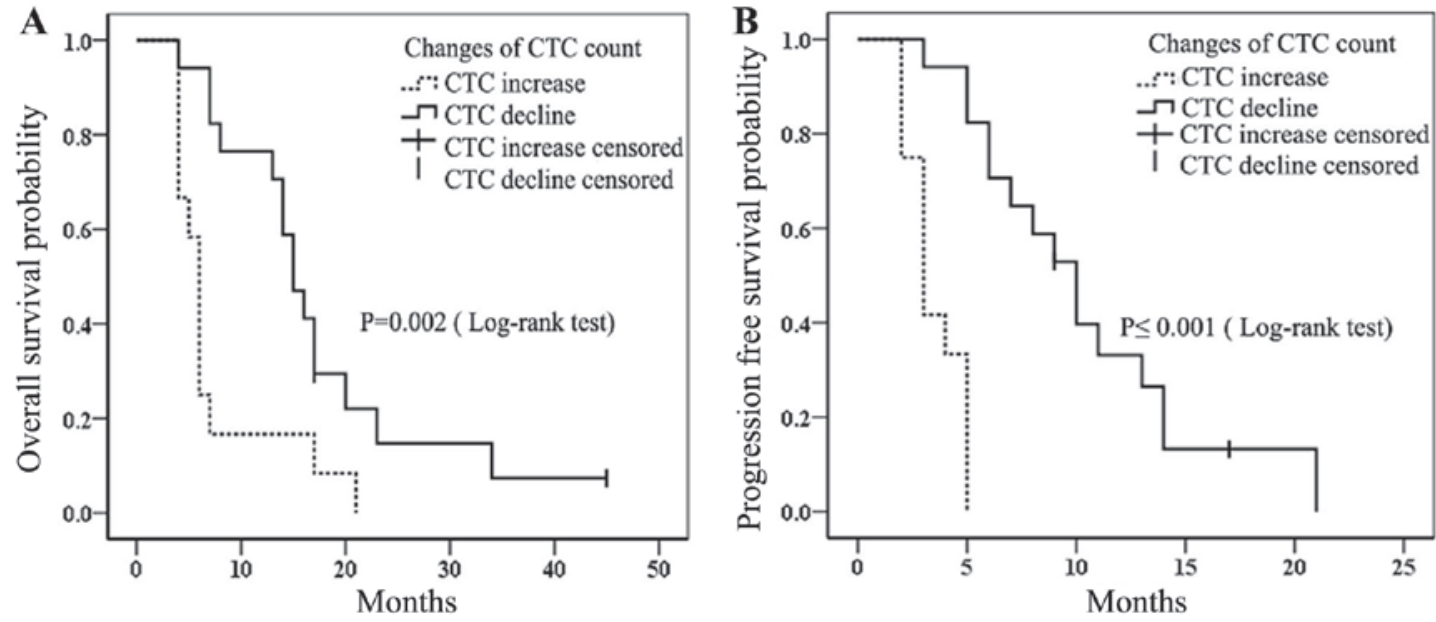

Figure 2. (A) Overall survival curve and (B) progression-free survival curve for 29 patients who were tested for CTCs before and after the first cycle of chemotherapy, according to decrease or increase in the CTC count. CTC, circulating tumor cell.

Associations between CTC count and survival. For all patients, the median PFS was 5 months (range, 2-43 months), and the median OS was 11 months (range, 4-45 months). In all patients, CTC count was significantly associated with PFS $(\mathrm{P}<0.001)$ and $\mathrm{OS}(\mathrm{P}<0.001)$ (Table III). Other factors that were significantly associated with PFS and OS on univariable analysis using Kaplan-Meier survival curves and the log-rank test were Eastern Cooperative Oncology Group performance status, tumor response and the serum levels of CEA and CA19-9 (Table III). The Kaplan-Meier survival curve for patients with CTC counts $\leq$ and $>2$ cells $/ 5 \mathrm{ml}$ peripheral blood are shown in Fig. 1. Patients with CTC counts $\leq 2$ cells $/ 5 \mathrm{ml}$ peripheral blood had a significantly longer median PFS and median OS compared with patients with CTC counts $>2$ cells $/ 5 \mathrm{ml}$ peripheral blood (median PFS, 11 vs. 4 months; and median OS, 17 vs. 7 months, respectively). In the 29 patients tested before and after the first cycle of chemotherapy, we found that patients exhibiting CTC count decline had significantly longer median PFS and OS compared with those with CTC count increase (median PFS, 10 vs. 3 months, respectively; $P \leq 0.001$; and median OS, 15 vs. 6 months, respectively; $\mathrm{P}=0.002$ ). (Table III; Fig. 2).
The multivariate analysis suggested that a CTC count at baseline of $>2$ cells $/ 5 \mathrm{ml}$ blood was an independent poor prognostic marker for PFS (hazard ratio $=2.81,95 \%$ confidence interval: 1.313-5.999, $\mathrm{P}=0.008$ ) and OS (hazard ratio $=3.59,95 \%$ confidence interval: $1.655-7.817, \mathrm{P}=0.001$ ) in all 59 patients (Table IV). However, in the 29 patients who were tested before and after the first cycle of chemotherapy, CTC count increase was an independent poor prognostic marker only for PFS (hazard ratio $=6.58,95 \%$ confidence interval: 1.37-31.6, $\mathrm{P}=0.019$ ) (Table IV).

\section{Discussion}

We demonstrated that a combination of immunomagnetic separation of CTCs followed by FITC-labeled anti-CK7/8/18/19 antibody staining and fluorescence microscope identification of CTCs may serve as a prognostic tool for PFS and OS in patients with advanced gastric cancer receiving chemotherapy. In particular, changes in the CTC count after the first cycle of chemotherapy may serve as a prognostic tool for PFS and may predict the sensitivity to chemotherapy regimens. 
Table IV. Hazard ratios for progression-free and overall survival.

\begin{tabular}{|c|c|c|c|c|c|c|}
\hline \multirow[b]{2}{*}{ Prognostic factors } & \multicolumn{3}{|c|}{ Progression-free survival } & \multicolumn{3}{|c|}{ Overall survival } \\
\hline & HR & $95 \% \mathrm{CI}$ & P-value & HR & $95 \% \mathrm{CI}$ & P-value \\
\hline \multicolumn{7}{|c|}{$\begin{array}{l}\text { Patients tested for CTCs } \\
\text { only prior to chemotherapy }\end{array}$} \\
\hline CTC count & & & 0.008 & & & 0.001 \\
\hline$\leq 2$ cells $/ 5 \mathrm{ml}$ blood & 1 & & & 1 & & \\
\hline$>2$ cells $/ 5 \mathrm{ml}$ blood & 2.81 & $1.313-5.999$ & & 3.59 & $1.655-7.817$ & \\
\hline CA19-9 ng/ml & & & 0.039 & & & 0.007 \\
\hline$\leq 37$ & 1 & & & 1 & & \\
\hline$>37$ & 1.912 & $1.033-3.537$ & & 2.613 & $1.307-5.222$ & \\
\hline CEA ng/ml & & & 0.001 & & & 0.001 \\
\hline$\leq 5$ & 1 & & & 1 & & \\
\hline$>5$ & 3.460 & $1.685-7.107$ & & 3.672 & $1.781-7.571$ & \\
\hline \multicolumn{7}{|c|}{$\begin{array}{l}\text { Patients tested for CTCs before and } \\
\text { after the first cycle of chemotherapy }\end{array}$} \\
\hline Changes in CTC & & & 0.019 & & & 0.638 \\
\hline Decline & 1 & & & 1 & & \\
\hline Increase & 6.58 & $1.37-31.6$ & & 0.774 & $0.266-2.251$ & \\
\hline CA19-9 ng/ml & & & 0.708 & & & 0.003 \\
\hline$\leq 37$ & 1 & & & 1 & & \\
\hline$>37$ & 0.851 & $0.366-1.977$ & & 0.182 & $0.059-0.563$ & \\
\hline CEA ng/ml & & & 0.001 & & & 0.395 \\
\hline$\leq 5$ & 1 & & & 1 & & \\
\hline$>5$ & 0.173 & $0.061-0.489$ & & 0.566 & $0.152-2.103$ & \\
\hline
\end{tabular}

CTC, circulating tumor cell; HR, hazard ratio; CI, confidence interval; CEA, carcinoembryonic antigen; CA19-9, carbohydrate antigen 19-9.

Solid tumor cells may enter the circulation, spread to other tissues and initiate metastasis. Thus, tumor cells may be detected in the peripheral blood. A variety of techniques and instruments were recently developed to enrich and isolate CTCs from the peripheral blood. These techniques generally rely on cell surface antigen expression for capturing CTCs or cell size to enrichment of CTCs by filtration techniques. CTC isolation methods and instruments were elaborately reported recently (8-11). In our study, we used commercially available immunomagnetic beads coated with the monoclonal antibody Ber-EP4 (12), which recognizes specific epitopes of the extracellular domain of the EpCAM molecule. EpCAM is expressed only in epithelium and malignant tumors derived from epithelia; thus, it may be used to enrich and isolate CTCs from blood.CKs are major structural proteins of epithelial cells and comprise at least 20 members. These CKs are primarily expressed in normal epithelial tissues, such as lung, gastrointestinal tract and kidney, as well as in cancer cells arising from these tissues (13-17). We adopted DAPI/FITC-labeled anti-CK7/8/18/19 antibody double staining to identify CTCs with fluorescence microscopy. No CK signal was observed in the blood samples from healthy donors, which verified the specificity of the used assays. In serial dilution assays, 10 SGC-7901 cells were detected in $5 \mathrm{ml}$ whole blood from
5 independent healthy donors. Most of the CTC recovery percentages were $>40 \%$. Low CTC recovery percentages may be correlated with the short half-life of CTCs in the blood (18) and relative long time of experimental procedure, although the viable tumor cells were counted prior to the tumor cell spiking experiments. In all the patients, The CTC-positive rate was $83.05 \%$. The high CTC-positive rate may be attributed to the fact that most of the patients in our study had stage IV disease. High CTC counts were also associated with poor tumor differentiation and high serum CEA levels. We hypothesized that poorly differentiated tumor cells exhibit strong invasiveness, and are therefore more likely to be transferred to the blood and distant organs. Our results are consistent with the available related literature $(19,20)$.

CTCs may be detected in the peripheral blood of patients with various cancers $(21,22)$; therefore, they may be used as an important auxiliary marker for the diagnosis of malignant solid tumors $(23,24)$. However, the majority of gastric cancer patients have middle- or late-stage disease at diagnosis. Hematogeneous tumor cell dissemination is a key step in cancer progression. Therefore, compared with its diagnostic value, CTC count may be more valuable in predicting the sensitivity to chemotherapeutic agents or the prognosis in patients with advanced gastric cancer. Several studies have reported 
that CTCs may be used as prognostic or predictive markers in patients with solid tumors, including gastric cancer $(20,25,26)$. In our study, we observed that patients with low CTC counts ( $\leq 2$ cells $/ 5 \mathrm{ml}$ peripheral blood) had a significantly longer median PFS and median OS compared with patients with high CTC counts ( $>2$ cells $/ 5 \mathrm{ml}$ peripheral blood). A high CTC count may also be an independent poor prognostic marker for PFS and OS.

In this study, we also investigated whether the changes in the CTC count were predictive of response to treatment, although only 29 patients were tested for CTCs before and after the first cycle of chemotherapy. In clinical practice, we often assess the OR to chemotherapy after the 3rd cycle of chemotherapy by CT scan or other imaging modalities. In fact, $\sim 30 \%$ of the patients are not likely to benefit from chemotherapy regimens. We consider that CTC detection may be more sensitive compared with $\mathrm{CT}$ and other imaging techniques in monitoring chemotherapeutic efficacy. Our results from small samples demonstrated that the mean CTC counts decreased significantly after the first cycle of chemotherapy in patients who obtained $\mathrm{CR}$ and PR, compared with those prior to chemotherapy $(\mathrm{P}=0.049)$. By contrast, in patients with PD, the mean CTC counts after the first cycle of chemotherapy increased significantly $(\mathrm{P}=0.021)$. We also found that patients with CTC count decline had significantly longer median PFS and OS compared with those with CTC count increase (Table III; Fig. 2A and B). In 29 patients who were tested for CTCs before and after the first cycle of chemotherapy, multivariate analysis suggested that CTC count increase is an independent poor prognostic marker only for PFS (hazard ratio $=6.58,95 \%$ confidence interval: $1.37-31.6, \mathrm{P}=0.019$ ) (Table IV). Our results may be partly consistent with the reports from Matsushita et al and other researchers (5,27-30). On the contrary, other studies considered changes in CTC count during the course of chemotherapy to not be predictive of clinical outcome or response to therapy $(31,32)$. The conflicting results between different studies may be associated with variations in the chemotherapeutic protocol or the different techniques used for detecting CTCs.

One of limitations of the present study is the relatively small size of the sample, which may explain the weak prognostic value of the changes in CTC count for OS in the 29 patients tested before and after the first cycle of chemotherapy. To further confirm the prognostic value of CTC testing in advanced gastric cancer patients, future large-sample, multicenter prospective studies are required.

\section{Acknowledgements}

The present study was partly supported by the Science and Technology Planning Project of Changzhou, Jiangsu Province (grant nos. CE20135051 and CE20165052), the Science and Technology Planning Project of Changzhou Health Bureau (grant nos. ZD201203 and ZD201616 ), the Research Project of the Health Department of Jiangsu Province (grant nos. Z201221 and Z201616), the 333 Talents Training Project of Jiangsu Province, the Key Medical Innovation Talents Training Project of Changzhou (grant no. 2016CZLJ021), and the Project of Jiangsu Province Sanitation Innovation Team (grant no. LJ201157).

\section{References}

1. Lordick F, Lorenzen S, Yamada Y and Ilson D: Optimal chemotherapy for advanced gastric cancer: Is there a global consensus? Gastric Cancer 17: 213-225, 2014.

2. Methy N, Bedenne L and Bonnetain F: Surrogate endpoints for overall survival in digestive oncology trials: Which candidates? A questionnaires survey among clinicians and methodologists. BMC cancer 10: 277, 2010.

3. Shanbhogue AK, Karnad AB and Prasad SR: Tumor response evaluation in oncology: Current update. J Comput Assist Tomogr 34: 479-484, 2010.

4. Rahbari NN, Aigner M, Thorlund K, Mollberg N, Motschall E, Jensen K, Diener MK, Büchler MW, Koch M and Weitz J: Meta-analysis shows that detection of circulating tumor cells indicates poor prognosis in patients with colorectal cancer. Gastroenterology 138: 1714-1726, 2010.

5. Thalgott M, Rack B, Eiber M, Souvatzoglou M, Heck MM, Kronester C, Andergassen U, Kehl V, Krause BJ, Gschwend JE, et al: Categorical versus continuous circulating tumor cell enumeration as early surrogate marker for therapy response and prognosis during docetaxel therapy in metastatic prostate cancer patients. BMC cancer 15: 458, 2015.

6. Okabe H, Tsunoda S, Hosogi H, Hisamori S, Tanaka E, Tanaka S and Sakai Y: Circulating tumor cells as an independent predictor of survival in advanced gastric cancer. Ann Surg Oncol 22: 3954-3961, 2015

7. Eisenhauer EA, Therasse P, Bogaerts J, Schwartz LH, Sargent D, Ford R, Dancey J, Arbuck S, Gwyther S, Mooney M, et al: New response evaluation criteria in solid tumours: Revised RECIST guideline (version 1.1). Eur J Cancer 45: 228-247, 2009.

8. Lu Y, Liang H, Yu T, Xie J, Chen S, Dong H, Sinko PJ, Lian S, Xu J, Wang J, et al: Isolation and characterization of living circulating tumor cells in patients by immunomagnetic negative enrichment coupled with flow cytometry. Cancer 121: 3036-3045, 2015.

9. Adams DL, Stefansson S, Haudenschild C, Martin SS, Charpentier M, Chumsri S, Cristofanilli M, Tang CM and Alpaugh RK: Cytometric characterization of circulating tumor cells captured by microfiltration and their correlation to the cellsearch ${ }^{\circledR}$ CTC test. Cytometry A 87: 137-144, 2015.

10. Yu M, Stott S, Toner M, Maheswaran S and Haber DA: Circulating tumor cells: Approaches to isolation and characterization. J Cell Biol 192: 373-382, 2011.

11. Gazzaniga P, Raimondi C, Nicolazzo C, Carletti R, di Gioia C, Gradilone A and Cortesi E: The rationale for liquid biopsy in colorectal cancer: A focus on circulating tumor cells. Expert Rev Mol Diagn 15: 925-932, 2015.

12. Antolovic D, Galindo L, Carstens A, Rahbari N, Büchler MW, Weitz $\mathbf{J}$ and Koch M: Heterogeneous detection of circulating tumor cells in patients with colorectal cancer by immunomagnetic enrichment using different EpCAM-specific antibodies. BMC Biotechnol 10: 35, 2010

13. Heo CK, Hwang HM, Ruem A, Yu DY, Lee JY, Yoo JS, Kim IG, Yoo HS, Oh S, Ko JH and Cho EW: Identification of a mimotope for circulating anti-cytokeratin 8/18 antibody and its usage for the diagnosis of breast cancer. Int J Oncol 42: 65-74, 2013.

14. Wang Y, Zhu JF, Liu YY and Han GP: An analysis of cyclin D1, cytokeratin 5/6 and cytokeratin 8/18 expression in breast papillomas and papillary carcinomas. Diagn Pathol 8: 8, 2013.

15. Strassen U, Hofauer B, Matsuba Y, Becker K, Mansour N and Knopf A: Bronchogenic cancer: It still exists. Laryngoscope: 2015.

16. Yin J, Wang Y, Yin H, Chen W, Jin G, Ma H, Dai J, Chen J, Jiang Y, Wang $\mathrm{H}$, et al: Circulating tumor cells enriched by the depletion of leukocytes with bi-antibodies in non-small cell lung cancer: Potential clinical application. PLoS One 10: e0137076, 2015.

17. Vaiopoulos AG, Kostakis ID, Gkioka E, Athanasoula KCh, Pikoulis E, Papalambros A, Christopoulos P, Gogas H, Kouraklis G and Koutsilieris M: Detection of circulating tumor cells in colorectal and gastric cancer using a multiplex PCR assay. Anticancer Res 34: 3083-3092, 2014.

18. Meng S, Tripathy D, Frenkel EP, Shete S, Naftalis EZ, Huth JF, Beitsch PD, Leitch M, Hoover S, Euhus D, et al: Circulating tumor cells in patients with breast cancer dormancy. Clin Cancer Res 10: 8152-8162, 2004.

19. Najjar F, Alammar M, Bachour M and Al-Massarani G: Circulating endothelial cells as a biomarker in non-small cell lung cancer patients: Correlation with clinical outcome. Int J Biol Markers 29: e337-e344, 2014. 
20. Huang X, Gao P, Sun J, Chen X, Song Y,Zhao J, Xu H and Wang Z: Clinicopathological and prognostic significance of circulating tumor cells in patients with gastric cancer: A meta-analysis. Int J Cancer 136: 21-33, 2015.

21. Cohen SJ, Punt CJ, Iannotti N, Saidman BH, Sabbath KD, Gabrail NY, Picus J, Morse M, Mitchell E, Miller MC, et al: Relationship of circulating tumor cells to tumor response, progression-free survival and overall survival in patients with metastatic colorectal cancer. J Clin Oncol 26: 3213-3221, 2008.

22. Botteri E, Sandri MT, Bagnardi V, Munzone E, Zorzino L, Rotmensz N, Casadio C, Cassatella MC, Esposito A, Curigliano G, et al: Modeling the relationship between circulating tumour cells number and prognosis of metastatic breast cancer. Breast Cancer Res Treat 122: 211-217, 2010.

23. Court CM, Ankeny JS, Hou S, Tseng HR and Tomlinson JS: Improving pancreatic cancer diagnosis using circulating tumor cells: Prospects for staging and single-cell analysis. Expert Rev Mol Diagn 15: 1491-1504, 2015.

24. Tang L, Zhao S, Liu W, Parchim NF, Huang J, Tang Y, Gan P and Zhong M: Diagnostic accuracy of circulating tumor cells detection in gastric cancer: Systematic review and meta-analysis. BMC Cancer 13: 314, 2013.

25. Cristofanilli M: Circulating tumor cells, disease progression and survival in metastatic breast cancer. Semin Oncol 33 (Suppl 9): S9-S14, 2006.

26. de Bono JS, Scher HI, Montgomery RB, Parker C, Miller MC, Tissing H, Doyle GV, Terstappen LW, Pienta KJ and Raghavan D: Circulating tumor cells predict survival benefit from treatment in metastatic castration-resistant prostate cancer. Clin Cancer Res 14: 6302-6309, 2008.
27. Camara O, Rengsberger M, Egbe A, Koch A, Gajda M, Hammer U, Jörke C, Rabenstein C, Untch M and Pachmann K: The relevance of circulating epithelial tumor cells (CETC) for therapy monitoring during neoadjuvant (primary systemic) chemotherapy in breast cancer. Ann Oncol 18: 1484-1492, 2007.

28. Das A, Kunkel M, Joudeh J, Dicker DT, Scicchitano A, Allen JE, Sarwani N, Yang Z, Kaifi J, Zhu J, et al: Clinico-pathological correlation of serial measurement of circulating tumor cells in 24 metastatic colorectal cancer patients receiving chemotherapy reveals interpatient heterogeneity correlated with CEA levels but independent of KRAS and BRAF mutation. Cancer Biol Ther 16: 709-713, 2015.

29. Matsushita D, Uenosono Y, Arigami T, Yanagita S, Nishizono Y, Hagihara T, Hirata M, Haraguchi N, Arima H, Kijima Y, et al: Clinical significance of circulating tumor cells in peripheral blood of patients with esophageal squamous cell carcinoma. Ann Surg Oncol 22: 3674-3680, 2015

30. Huang X, Gao P, Song Y, Sun J, Chen X, Zhao J, Liu J, Xu H and Wang Z: Relationship between circulating tumor cells and tumor response in colorectal cancer patients treated with chemotherapy: A meta-analysis. BMC Cancer 14: 976, 2014.

31. Kubisch I, de Albuquerque A, Schuppan D, Kaul S, Schaich M and Stölzel U: Prognostic role of a multimarker analysis of circulating tumor cells in advanced gastric and gastroesophageal adenocarcinomas. Oncology 89: 294-303, 2015.

32. Fei F, Du Y, Di G, Wu J and Shao Z: Are changes in circulating tumor cell (CTC) count associated with the response to neoadjuvant chemotherapy in local advanced breast cancer? A meta-analysis. Oncol Res Treat 37: 250-254, 2014. 